\title{
Patients' View on the Management of Papillary Thyroid Microcarcinoma: Active Surveillance or Surgery
}

\author{
Yusaku Yoshida, Kiyomi Horiuchi, and Takahiro Okamoto
}

Background: Clinical practice guidelines have endorsed both active surveillance and surgery as viable management options for papillary thyroid microcarcinoma (PTMC). However, patients' perceptions on the options have rarely been addressed.

Methods: A cross-sectional survey was conducted on 50 patients with PTMC who were under either active surveillance $(n=20)$ or postoperative follow-up $(n=30)$. The primary outcome was anxiety, which was measured using the State-Trait Anxiety Inventory (STAI). A questionnaire that comprised six items about PTMCrelated symptoms and concerns, which were measured with a visual analog scale, was also administered. Cohen's $d$ effect size was calculated to express group differences. Multiple regression analysis was used to examine the relationships between state anxiety and other variables.

Results: The median age and observation period were 61.5 years (range, $40-83$ years) and 4.1 years (range, 0-8.6 years), respectively. The female/male ratio was 38/12. Compared with the surgery group, the active surveillance group showed higher scores in both state anxiety and trait anxiety, with corresponding effect sizes of 0.55 (confidence interval $[\mathrm{CI}]-0.03$ to $1.1 ; p=0.068$ ) and 0.63 (CI $0.02-1.2 ; p=0.037$ ), respectively. Trait anxiety $(\beta=0.83)$ and observation time $(\beta=-1.57)$ were the significant predictors of state anxiety. Moderate effect sizes were observed for "discomfort in the neck" (-0.53; CI -1.11 to 0.04$)$; "weak voice" ( -0.46 ; CI -1.03 to 0.12$)$; and "nervous about neck appearance" (-0.64; CI -1.23 to -0.07$)$, in favor of active surveillance.

Conclusions: State anxiety among patients with PTMC seemed to be a reflection of an individual's trait rather than management. Understanding the patients' view appears to be key to improve shared decision-making.

Keywords: papillary thyroid microcarcinoma, patient-reported outcome, active surveillance, effect size

\section{Introduction}

$\mathbf{T}$ HE INCIDENCE OF thyroid cancer is increasing worldwide, including in Japan (1-3). This increase may mostly be due to the growing number of incidental findings encountered with the increasing use of regular health checkups; screening tests such as ultrasound for carotid arteriosclerosis or computed tomography scans for chest lesions, among others. Of these incidental findings, papillary thyroid carcinoma (PTC) accounts for the majority of the malignant lesions. PTC is generally characterized as a slowgrowing indolent tumor, which may not even be harmful, as several studies demonstrated that PTC is frequently found on autopsy (4-6). Davies and Welch further pointed out that many of the newly diagnosed PTC patients had tumors measuring $\leq 1 \mathrm{~cm}$ in diameter, hence papillary thyroid microcarcinoma (PTMC) (3).

Investigators at two institutes in Japan pioneered clinical studies on the active surveillance of PTMC without lymph node or distant metastasis (T1aNOM0) (7-9). Ito et al. followed 1235 patients who did not undergo surgery for PMTC and reported that $8.0 \%$ experienced a tumor enlargement by $\geq 3 \mathrm{~mm}$ in diameter, and 3.8\% developed lymph node metastasis 10 years after the first diagnosis (8). Sugitani and colleagues observed 480 PMTC in 384 patients after a mean follow-up of 6.8 years; they estimated that $7.3 \%$ of the lesions had a probability of enlargement at 10 years after the diagnosis (9). Based on these findings, the Japanese Clinical

Department of Breast and Endocrine Surgery, Tokyo Women's Medical University, Tokyo, Japan.

(C) Yusaku Yoshida et al. 2020; Published by Mary Ann Liebert, Inc. This Open Access article is distributed under the terms of the Creative Commons Attribution Noncommercial License (http://creativecommons.org/licenses/by-nc/4.0/) which permits any noncommercial use, distribution, and reproduction in any medium, provided the original author(s) and the source are cited. 
Practice Guidelines for Thyroid Tumors introduced active surveillance without surgery as one of the management options for PTMC $(10,11)$, which was also recognized as an alternative option in the revised guidelines by the American Thyroid Association (12).

Patients on active surveillance can avoid risks of complications and late consequences associated with surgery, although they may have concerns about disease progression despite their involvement in the shared decision process. On the contrary, those who underwent surgery may be assured because they can be considered cured, yet they may experience sequelae due to the operation.

To clarify the concerns associated with the management of PTMC from the patient's perspective, we conducted a crosssectional study on the patient-reported outcomes of PTMC managed with active surveillance or surgery.

\section{Materials and Methods}

\section{Design and patients}

A cross-sectional survey was conducted on patients with PTMC who visited our outpatient clinic between September 1, 2016, and April 30, 2017. The study participants were either on active surveillance or postoperative follow-up for their PTMC, which was defined as measuring $\leq 1 \mathrm{~cm}$ in maximum diameter, without any apparent lymph node or distant metastases (T1aN0M0). The time of surgery was limited to the period between January 2011 and December 2013 for patients who underwent an operation (surgery group). In contrast, active surveillance was initiated between January 2006 and December 2016 for those who remained under follow-up without surgery (active surveillance group).

\section{Observations and measurements}

The primary outcome was anxiety, which was measured using the new edition of the State-Trait Anxiety Inventory (STAI) Form JYZ. The STAI was a self-administered instrument with two subscales to separately assess anxiety-associated conditions at a given time (state anxiety) and anxiety unique to an individual's personality (trait anxiety) $(13,14)$. The inventory has 20 items for each subscale, with a 4-point Likert scale from "almost never" to "almost always." Therefore, the possible scores for each domain can range from a minimum of 20 to a maximum of 80 . Test/retest correlation coefficients were reported to vary from 0.31 to 0.86 , and internal consistency alpha coefficients were quite high, ranging from 0.86 to 0.95 (15).

The secondary outcomes were symptoms and concerns related to PTMC. A questionnaire that was explicitly developed to measure the outcomes of this study included six questions, as follows: (1) "Do you have any discomfort in your neck?" (2) "Are you satisfied with the course of the current cancer treatment or active surveillance?" (3) "Do you feel anxious about the disease?" (4) "Do you have trouble with swallowing?" (5) "Do you have a weak voice?" and (6) "Are you nervous about the appearance of your neck?" Items 1, 3, 4, and 5 were adopted and modified from the items in the thyroid cancer quality-of-life (THYCA-QoL) instrument, a disease-specific health-related quality-of-life questionnaire for thyroid cancer survivors (16). Since our intention was not to measure the same property (quality of life) of patients with PTMC, other items from THYCA-QoL were not adopted, while items 2 and 6 were questions that were specifically added. The patients were asked to respond to each item using a visual analog scale (VAS) to evaluate how they felt at the time of the survey; the VAS ranged from 0 ("not at all") to 100 ("very much so"). Consented patients were asked to complete the questionnaires immediately after the office visits for medical examination.

The following demographic variables, as well as diseaserelated data, were collected from the electronic medical records of each participant: age, sex, diagnosis, TNM staging, and observation duration. Time zero was defined as the day of surgery for the surgery group, and the day of shared decisionmaking on nonoperative management for the active surveillance group. The extent of thyroidectomy and lymph node dissection, as well as surgical complications, was ascertained for each case in the surgery group.

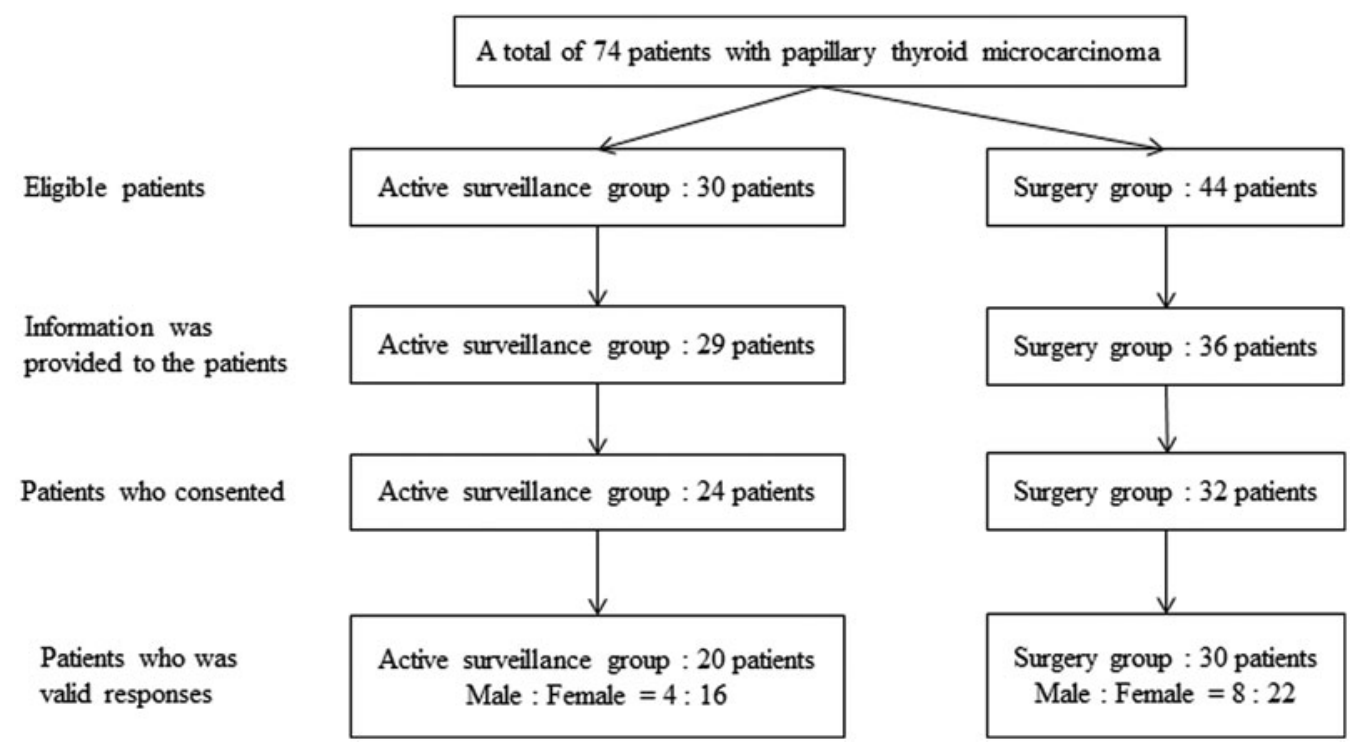

FIG. 1. Selection of study participants. 
Table 1. Patient Characteristics

\begin{tabular}{|c|c|c|c|}
\hline & $\begin{array}{c}\text { Active } \\
\text { surveillance } \\
(\mathrm{n}=20)\end{array}$ & $\begin{array}{l}\text { Surgery } \\
(\mathrm{n}=30)\end{array}$ & $\mathrm{p}$ \\
\hline $\begin{array}{l}\text { Age (years): median } \\
\text { (range) }\end{array}$ & $61(42-83)$ & $\begin{array}{c}62.5 \\
(40-76)\end{array}$ & 0.54 \\
\hline Sex: (female/male) & $16 / 4$ & $22 / 8$ & 0.74 \\
\hline $\begin{array}{c}\text { Tumor size }(\mathrm{mm}) \text { : } \\
\text { median (range) }\end{array}$ & $7.5(4-10)$ & $8(4-10)$ & 0.12 \\
\hline Multicentric & 1 & 6 & 0.21 \\
\hline Thyroidectomy & Not relevant & & - \\
\hline $\begin{array}{l}\text { Lobectomy } \\
\text { Isthmusectomy }\end{array}$ & & $\begin{array}{r}24 \\
1\end{array}$ & \\
\hline Subtotal & & 1 & \\
\hline Total & & 4 & \\
\hline Lymph node dissection & Not relevant & & 一 \\
\hline Pre-/paratracheal & & 30 & \\
\hline Lateral & & 0 & \\
\hline None & & 0 & \\
\hline $\begin{array}{l}\text { Observation time } \\
\text { (years): median } \\
\text { (range) }\end{array}$ & $4.05(0-8.6)$ & $\begin{array}{c}4.25 \\
(2.8-6.2)\end{array}$ & 0.50 \\
\hline $\begin{array}{l}\text { Disease progression or } \\
\text { relapse of PTMC }\end{array}$ & 0 & 0 & - \\
\hline $\begin{array}{l}\text { Levothyroxine } \\
\text { medication }\end{array}$ & 0 & 12 & $<0.01$ \\
\hline TSH level & & & 0.17 \\
\hline Low & 0 & 1 & \\
\hline Normal & 19 & 24 & \\
\hline High & 1 & 5 & \\
\hline
\end{tabular}

PTMC, papillary thyroid microcarcinoma; TSH, thyrotropin.

\section{Statistical analyses}

The demographic and outcomes data between the active surveillance and surgery groups were compared using the Fisher's exact test for categorical variables and either the Student's $t$-test or the Wilcoxon rank-sum test for continuous variables. For comparisons of numerical data, the assumptions of Gaussian distribution and homoscedasticity were examined by the Shapiro-Wilk test and the F-test, respectively. The between-group differences in the STAI and VAS scores were expressed by Cohen's $d$ effect size, in which the mean difference in scores was divided by the pooled standard deviation (SD). An effect size of 0.2 was considered small; 0.5 was considered moderate; and 0.8 was considered large $(17,18)$. Multiple linear regression analyses were used to explore the associations between state anxiety and other variables. Since our primary interest was the relationship between anxiety (state anxiety) and management, we initially constructed the hierarchically well-formulated model, with state anxiety as the dependent variable and age, group, observation period, and trait anxiety as the explanatory vari- ables, as well as their interaction terms with a group $(19,20)$. All analyses were performed using JMP Pro version 14 (SAS Institute, Inc., Cary, NC). A two-tailed $p$-value of $<0.05$ was considered statistically significant.

\section{Ethical considerations}

The study was approved by the Ethics Committee of Tokyo Women's Medical University (No. 4070). Each patient provided written informed consent before participating in the study.

\section{Results}

Seventy-four potentially eligible patients visited the outpatient clinic during the survey period. Nine patients did not have the opportunity of being asked to participate in the survey. Among 65 patients to whom the nature of the study was explained, 56 patients consented to participate. Valid responses were obtained from 20 patients in the active surveillance group and 30 patients in the surgery group (Fig. 1).

\section{Patient characteristics}

As shown in Table 1, 80\% of the active surveillance group and $73 \%$ of the surgery group were women. The median age and observation period were 61.0 years (range, $42-83$ years) and 4.05 years (range, $0-8.6$ years), respectively, in the active surveillance group; and 62.5 years (range, $40-76$ years) and 4.25 years (range, $2.8-6.2$ years), respectively, in the surgery group. There were no apparent differences in the distributions of these variables between the groups. Multicentric PTMC was more frequent in the surgery group (20\%) than in the active surveillance group (5\%), although the difference was not statistically significant $(p=0.21)$. As for the extent of thyroidectomy in the surgery group, lobectomy was carried out for 24 patients (80\%), including 2 patients with multicentric disease. All of the patients in the surgery group also underwent prophylactic pre- and paratracheal lymph node dissection. None of the patients experienced disease progression (active surveillance group) or relapse of the disease (surgery group).

\section{Anxiety}

The mean \pm SD of the state anxiety score was higher in the active surveillance group $(41.3 \pm 11.1)$ than in the surgery group (35.9 \pm 9.1$)$, although the difference was not statistically significant $(p=0.068)$, and its effect size was 0.55 with a $95 \%$ confidence interval (CI) between -0.03 and 1.1. Trait anxiety score (mean $\pm \mathrm{SD}$ ) was $41.2 \pm 10.3$ in the active surveillance group and $35.2 \pm 9.0$ in the surgery group $(p=0.037)$, and its effect size was 0.63 (CI $0.05,1.2)$

Table 2. State-Trait Anxiety Inventory Scores

\begin{tabular}{lcccc}
\hline & Active surveillance $(\mathrm{n}=20)$ & Surgery $(\mathrm{n}=30)$ & Effect size & $\mathrm{p}$ \\
\hline State anxiety & $41.3(11.1)$ & $35.9(9.1)$ & $0.55(-0.03$ to 1.1$)$ & 0.068 \\
Trait anxiety & $41.2(10.3)$ & $35.2(9.0)$ & $0.63(0.05$ to 1.2$)$ & 0.037 \\
\hline
\end{tabular}

STAI scores were expressed as mean (SD). The numbers in parentheses represent a 95\% confidence interval. SD, standard deviation; STAI, State-Trait Anxiety Inventory. 


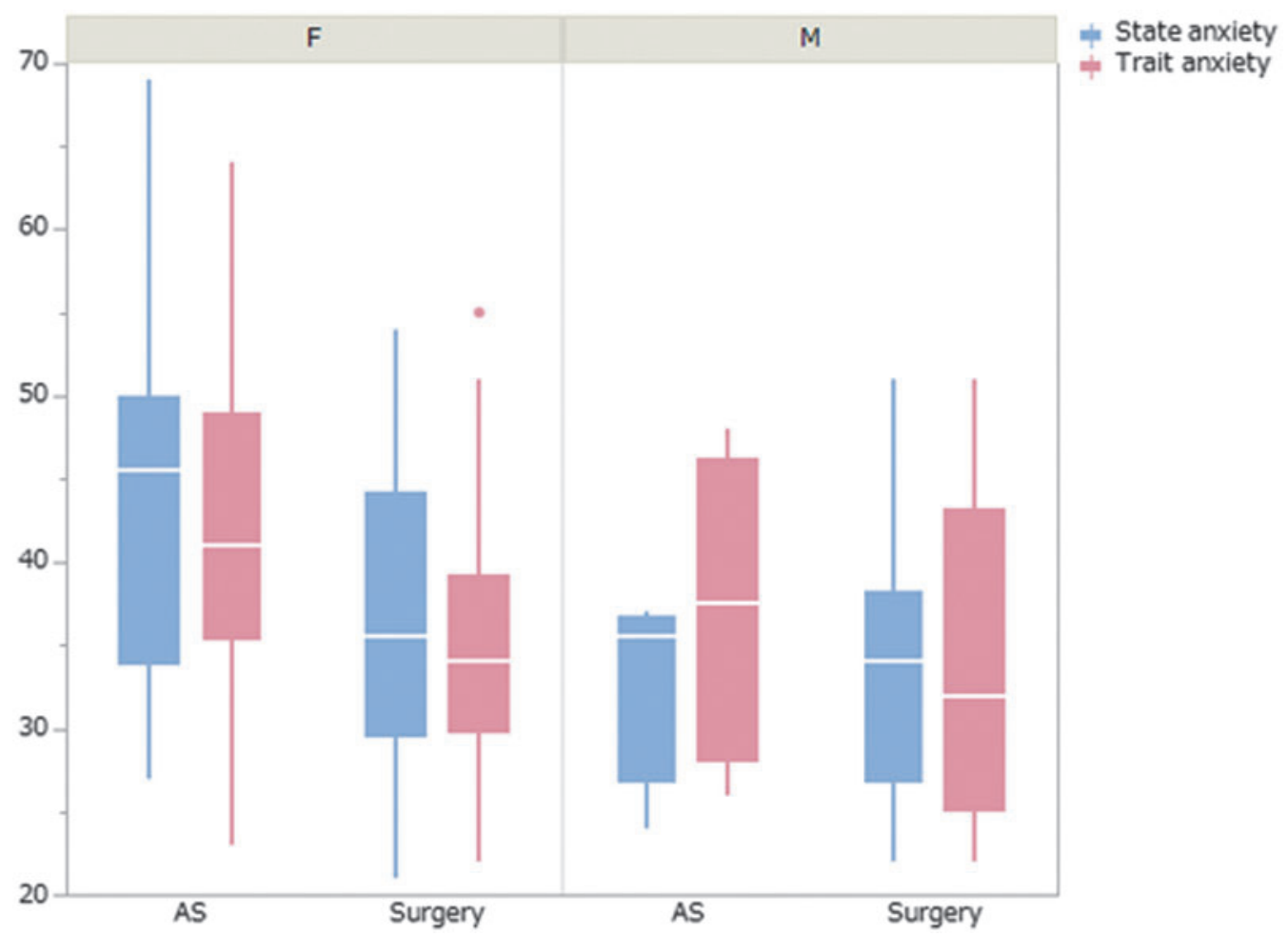

FIG. 2. State and trait anxiety scores by sex and management. AS, active surveillance; F, female patients; M, male patients.

(Table 2). Female patients in the active surveillance group showed higher scores in state anxiety, compared with those in the surgery group (effect size 0.69 CI $0.02-1.3$ ); whereas male patients exhibited no apparent difference in the scores

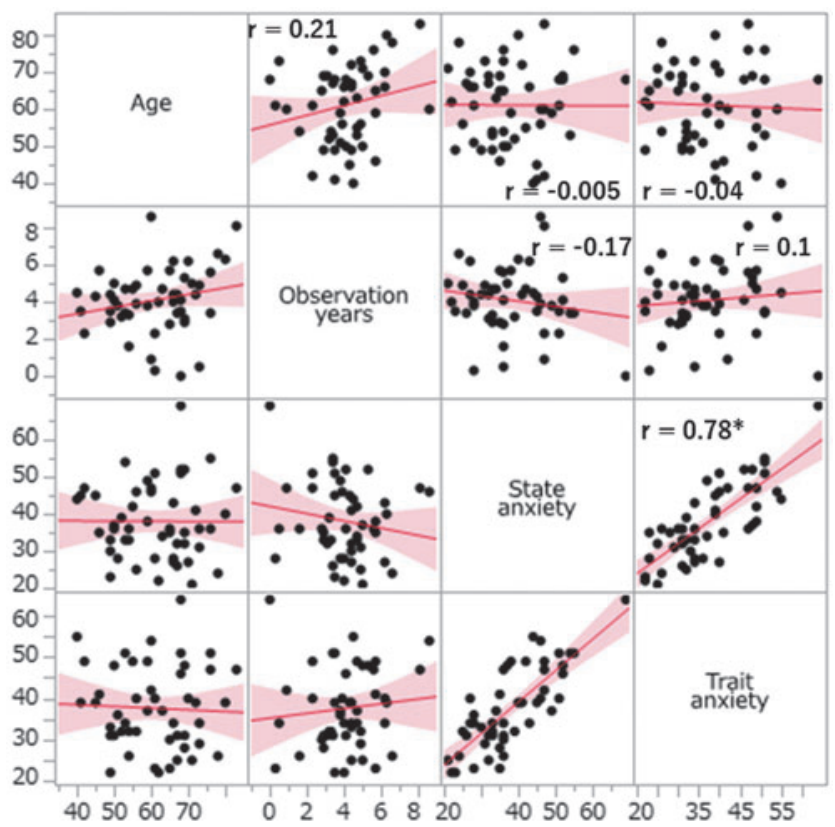

FIG. 3. Scatter plot matrix of age, observation years, state anxiety score, and trait anxiety score ( $r$ : Pearson's correlation coefficient). between the groups (effect size -0.15 ; CI -1.4 to 1.0) (Fig. 2). The distributions and correlation coefficients of age, observation period, state anxiety score, and trait anxiety score are shown in Figure 3. State anxiety score was significantly associated with trait anxiety score (Pearson's $r=0.78, p<0.01$ ).

Multiple regression analyses with and without interaction terms indicated that there was no significant interaction (multiple-partial $F$ test, $F_{4}, 40,0.95=0.34, p>0.05$ ). The model without interaction terms $\left(F_{5}, 44=20.2, p<0.01\right.$, $R^{2}=0.70$ ) showed that the group variable was not associated with state anxiety, while trait anxiety was positively $(\beta=0.83, p<0.001)$ and observation time was negatively $(\beta=-1.57, p=0.003)$ associated with the outcome (Table 3).

\section{Symptoms and concerns related to PTMC}

As shown in Figure 4, the estimated effect size, based on the responses on the VAS, was -0.53 ( $\mathrm{CI}-1.11$ to 0.04 ) for "discomfort in the neck"; -0.36 (CI $-0.92,0.21)$ for "satisfied with the clinical management"; 0.3 (CI -0.26 to 0.88 ) for "anxious about the disease"; 0.08 (CI -0.49 to 0.64$)$ for "troubles with swallowing"; and $-0.46(\mathrm{CI}-1.03$ to 0.12$)$ for "weak voice." The group difference reached a statistically significant level only for "nervous about neck appearance," with an effect size of -0.64 (CI -1.23 to -0.07 ).

\section{Discussion}

Patient view or quality of life has been recognized as an important outcome in clinical studies, as well as in daily practice. Short-term health-related quality of life among 
Table 3. Multiple Regression Analysis with State AnXIETy SCORE as a Dependent Variable

\begin{tabular}{lccc}
\hline Variables & $\begin{array}{c}\text { Coefficient } \\
(\beta)\end{array}$ & $\begin{array}{c}\text { Standard } \\
\text { error }\end{array}$ & $\mathrm{p}$ \\
\hline Intercept & 5.76 & 6.21 & 0.36 \\
Trait anxiety score & 0.83 & 0.09 & $<0.0001$ \\
Age (years) & 0.09 & 0.08 & 0.26 \\
Sex (female = 1/male=0) & 2.61 & 1.99 & 0.19 \\
Group (active & -0.46 & 1.82 & 0.80 \\
$\quad$ surveillance =1/ & & & \\
$\quad$ surgery=0) & & & \\
Observation time (years) & -1.57 & 0.51 & 0.003 \\
\hline
\end{tabular}

$R^{2}=0.70$.

thyroid cancer survivors is affected by surgery, thyroid hormone withdrawal for radioactive iodine treatment, and thyrotropin suppression therapy; in contrast, the results for long-term survivors have been contradicting (21). In their cohort of patients with differentiated thyroid carcinoma, Hedman et al. reported that $48 \%$ of the participants continued to have concerns about having a recurrence, even after 14-17 years after the diagnosis, although the investigators also observed, in $89 \%$ of the survivors, that the disease did not influence their view on life (22). Sawka et al. found that even low-risk thyroid cancer survivors, to some extent, had concerns and unmet information needs about the disease, which may impact their daily life (23-25).

However, concerning the management of PTMC, relevant studies and clinical practice guidelines have focused on the natural history of the tumor itself (i.e., disease progression) and none had looked into the patients' view on being managed by either active surveillance or surgical treatment in the manner of the present study. Davies et al. recently reported their qualitative study that addressed patient experiences of 243 patients with PTMC (26). Thirty-seven percent of respondents described their worry about cancer as occurring sometimes or more frequently, but $60 \%$ said their worry was less than it was when they first found out about their cancer. Moreover, $83 \%$ of respondents agreed that undergoing active surveillance was the best decision (26). Compared with that study, our present investigation is unique because we had a surgical group for comparison (27). We observed that the state anxiety score was higher in the active surveillance group than that in the surgery group. Although the difference did not reach statistical significance, its effect size $(0.55)$ was large enough to be clinically meaningful. Patients in the active surveillance group also exhibited higher scores for trait anxiety compared with those in the surgery group resulting in an effect size of 0.63 , which was statistically and clinically significant. Multiple regression analysis showed that trait anxiety and observation time are independent predictors of state anxiety, regardless of the management. The group difference in trait anxiety seemed to have been reflected in the group difference in state anxiety. In other words, patient traits predisposing to feel anxiety may explain the group difference in state anxiety rather than the management itself.

Another unique attempt in this study was to measure the symptoms and concerns related to the management of PTMC. Moderate effect sizes associated with a preference for surgery consisted of being "anxious about the disease," whereas those in favor of active surveillance mentioned "discomfort in the neck," "weak voice," and "neck appearance." These observations were valuable lessons for us because we expected that our operative approach of using minimal exposure (i.e., lobectomy along with paratracheal lymph node dissection) and neuromonitoring devices in most patients would have a low likelihood of causing any burden to the patients. Investigators from the University of Wisconsin reported that patient-perceived voice changes were frequent $(57 \%)$ after thyroidectomy, even in the absence of vocal cord paralysis (28), and that $80 \%$ of patients had at least one swallowing-related symptom (29). Physicians have underestimated the prevalence of physical symptoms associated with thyroid cancer treatments (30).

A few limitations need to be considered when interpreting our findings. First, the timing of administering the questionnaires might affect the results. The participants likely had the

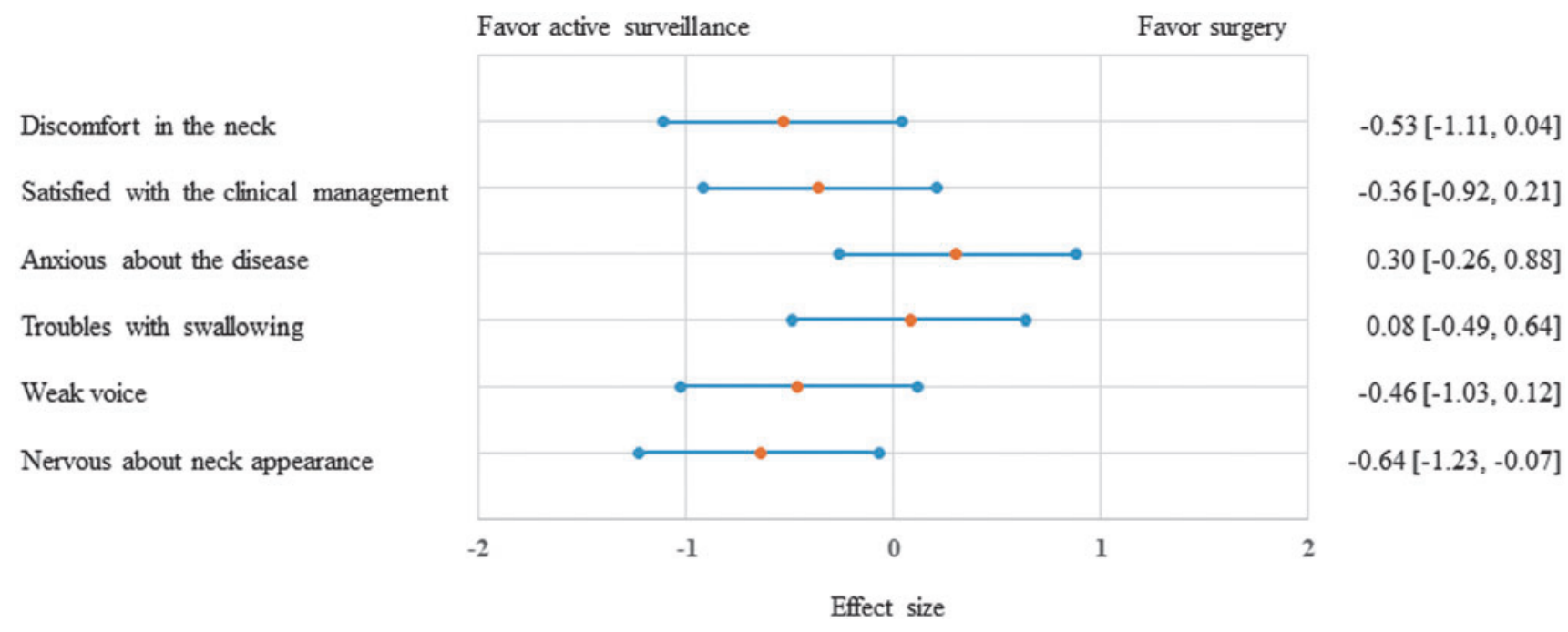

FIG. 4. Effect size of management on symptoms and concerns related to PTMC measured by visual analog scales. PTMC, papillary thyroid microcarcinoma. 
least anxiety because they were just assured that there was no progression or recurrence of their disease by medical examination. Second, patients' anxiety might also be explained by other factors such as variations in the ways that physicians provided explanations to the patients, as well as in the clinical management strategies, such as follow-up examinations during the postoperative observational period (31). Finally, the study was underpowered to detect a clinically meaningful difference in some of the effect sizes because of the limited number of patients under active surveillance who were available for the survey.

Active surveillance may be a viable or even a desirable option for PTMC, and its indications have been expanding to include larger tumors $(32,33)$. Understanding the patients' view is critical to convey information and use appropriate words in physician/patient communication to improve shared decision-making $(30,34)$.

\section{Acknowledgment}

The authors are grateful to Yasuko Nozoe for her managerial work.

\section{Author Disclosure Statement}

No competing financial interests exist.

\section{Funding Information}

This study was not supported by any external funding.

\section{References}

1. Hori M, Matsuda T, Shibata A, Katanoda K, Sobue T, Nishimoto H; Japan Cancer Surveillance Research Group 2015 Cancer incidence and incidence rates in Japan in 2009: a study of 32 population-based cancer registries for the Monitoring of Cancer Incidence in Japan (MCIJ) project. Jpn J Clin Oncol 45:884-891.

2. Ahn HS, Kim HJ, Welch HG 2014 Korea's thyroid-cancer "epidemic" - screening and overdiagnosis. N Engl J Med 371:1765-1767.

3. Davies L, Welch HG 2006 Increasing incidence of thyroid cancer in the United States, 1973-2002. JAMA 295:21642167.

4. Sampson RJ, Woolner LB, Bahn RC, Kurland LT 1974 Occult thyroid carcinoma in Olmsted County, Minnesota: prevalence at autopsy compared with that in Hiroshima and Nagasaki, Japan. Cancer 34:2072-2076.

5. Harach HR, Franssila KO, Wasenius VM 1985 Occult papillary carcinoma of the thyroid. A "normal" finding in Finland. A systematic autopsy study. Cancer 56:531-538.

6. Martinez-Tello FJ, Martinez-Cabruja RM, FernandezMartin J, Lasso-Oria C, Ballestin-Carcavilla C 1993 Occult carcinoma of the thyroid: a systematic autopsy study from Spain of two series performed with two different methods. Cancer 71:4022-4029.

7. Ito $\mathrm{Y}$, Miyauchi A, Inoue H, Fukushima M, Kihara M, Higashiyama T, Tomoda C, Takamura Y, Kobayashi K, Miya A 2010 An observational trial for papillary thyroid microcarcinoma in Japanese patients. World J Surg 34:28-35.

8. Ito Y, Miyauchi A, Kihara M, Higashiyama T, Kobayashi K, Miya A 2014 Patient age is significantly related to the progression of papillary microcarcinoma of the thyroid under observation. Thyroid 24:27-34.
9. Fukuoka O, Sugitani I, Ebina A, Toda K, Kawabata K, Yamada K 2016 Natural history of asymptomatic papillary thyroid microcarcinoma: time-dependent changes in calcification and vascularity during active surveillance. World $\mathbf{J}$ Surg 40:529-537.

10. Takami H, Ito Y, Okamoto T, Yoshida A 2011 Therapeutic strategy for differentiated thyroid carcinoma in Japan based on a newly established guideline managed by the Japanese Society of Thyroid Surgeons and Japanese Association of Endocrine Surgeons. World J Surg 35:111-121.

11. Takami H, Ito Y, Noguchi H, Okamoto T 2012 Treatment of Thyroid Tumor: Japanese Clinical Guidelines. Springer, Tokyo, pp 1-310.

12. Haugen BR, Alexander EK, Bible KC, Doherty GM, Mandel SJ, Nikiforov YE, Pacini F, Randolph GW, Sawka AM, Schlumberger M, Schuff KG, Sherman SI, Sosa JA, Steward DL, Tuttle RM, Wartofsky L 20162015 American Thyroid Association Management Guidelines for Adult Patients with Thyroid Nodules and Differentiated Thyroid Cancer: the American Thyroid Association Guidelines Task Force on Thyroid Nodules and Differentiated Thyroid Cancer. Thyroid 26:1-139.

13. Hidano N, Fukuhara M, Iwawaki M, Soga S, Spielberger C 2000 Manual for the State-Trait Anxiety Inventory-Form JYZ [in Japanese]. Jitsumu Kyoiku-Shuppan, Tokyo.

14. Spielberger CD, Gorsuch RL, Lushene R, Vagg PR, Jacobs GA 1983 Manual for the State-Trait Anxiety Inventory (Form Y). Consulting Psychologists Press, Palo Alto, CA.

15. Julian LJ 2011 Measures of anxiety: State-Trait Anxiety Inventory (STAI), Beck Anxiety Inventory (BAI), and Hospital Anxiety and Depression Scale-Anxiety (HADSA). Arthritis Care Res 63:S467-S472.

16. Husson O, Haak HR, Mols F, Nieuwenhuijzen GA, Nieuwlaat WA, Reemst PH, Huysmans DA, Toorians AW, van de Poll-Franse LV 2013 Development of a diseasespecific health-related quality of life questionnaire (THYCA-QoL) for thyroid cancer survivors. Acta Oncol 52:447-454.

17. Ellis PD 2010 The Essential Guide to Effect Sizes: Statistical Power, Meta-Analysis, and the Interpretation of Research Results. Cambridge University Press, Cambridge.

18. Norman GR, Sloan JA, Wyrwich KW 2003 Interpretation of changes in health-related quality of life: the remarkable universality of half a standard deviation. Med Care 41:582592.

19. Kleinbaum DG 1994 Logistic Regression: A Self-Learning Text. Springer-Verlag, New York.

20. Kleinbaum DG, Kupper LL, Muller KE 1988 Applied Regression Analysis and Other Multivariable Methods. Second edition. Duxbury Press, Belmont, CA.

21. Husson O, Haak HR, Oranje WA, Mols F, Reemst PH, van de Poll-Franse LV 2011 Health-related quality of life among thyroid cancer survivors: a systematic review. Clin Endocrinol 75:544-554.

22. Hedman C, Djärv T, Strang P, Lundgren CI 2016 Determinants of long-term quality of life in patients with differentiated thyroid carcinoma: a population-based cohort study in Sweden. Acta Oncol 55:365-369.

23. Sawka AM, Tsang RW, Brierley JD, Rotstein L, Segal P, Ezzat S, Goldstein DP 2016 Concerns of low-risk thyroid cancer survivors. Acta Oncol 55:1252-1253.

24. Sawka AM, Brierley JD, Tsang RW, Rotstein L, Ezzat S, Goldstein DP 2016 Unmet information needs of low-risk thyroid cancer survivors. Thyroid 26:474-475. 
25. Sawka AM, Ezzat S, Goldstein DP 2016 Exploring the life impact of treated low-risk thyroid cancer. Endocr Pract 22: 513-514.

26. Davies L, Roman BR, Fukushima M, Ito Y, Miyauchi A 2019 Patient experience of thyroid cancer active surveillance in Japan. JAMA Otolaryngol Head Neck Surg 145: 363-370.

27. Sawka AM, Goldstein DP 2019 Papillary thyroid microcarcinoma: if it is such a good cancer, why operate? JAMA Otolaryngol Head Neck Surg 145:371-372.

28. Kletzien H, Macdonald CL, Orne J, Francis DO, Leverson G, Wendt E, Sippel RS, Connor NP 2018 Comparison between patient-perceived voice changes and quantitative voice measures in the first postoperative year after thyroidectomy: a secondary analysis of a randomized clinical trial. JAMA Otolaryngol Head Neck Surg 144:995-1003.

29. Krekeler BN, Wendt E, Macdonald C, Orne J, Francis DO, Sippel R, Connor NP 2018 Patient-reported dysphagia after thyroidectomy: a qualitative study. JAMA Otolaryngol Head Neck Surg 144:342-348.

30. James BC, Aschebrook-Kilfoy B, White MG, Applewhite MK, Kaplan SP, Angelos P, Kaplan EL, Grogan RH 2018 Quality of life in thyroid cancer-assessment of physician perceptions. J Surg Res 226:94-99.

31. Hedman C, Strang P, Djärv T, Widberg I, Lundgren CI 2017 Anxiety and fear of recurrence despite a good prog- nosis: an interview study with differentiated thyroid cancer patients. Thyroid 27:1417-1423.

32. Sawka AM, Ghai S, Tomlinson G, Rotstein L, Gilbert R, Gullane P, Pasternak J, Brown D, de Almeida J, Irish J, Chepeha D, Higgins K, Monteiro E, Jones JM, Gafni A, Goldstein DP 2018 A protocol for a Canadian prospective observational study of decision-making on active surveillance or surgery for low-risk papillary thyroid cancer. BMJ Open 8:e020298.

33. Sakai T, Sugitani I, Ebina A, Fukuoka O, Toda K, Mitani H, Yamada K 2019 Active surveillance for T1bN0M0 papillary thyroid carcinoma. Thyroid 29:59-63.

34. Easley J, Miedema B, Robinson L 2013 It's the "good" cancer, so who cares? Perceived lack of support among young thyroid cancer survivors. Oncol Nurs Forum 40:596-600.

Address correspondence to:

Yusaku Yoshida, MD

Department of Breast and Endocrine Surgery

Tokyo Women's Medical University

8-1 Kawada-cho

Shinjuku-ku

Tokyo 162-8666

Japan

E-mail: yoshida.yusaku@twmu.ac.jp 